\title{
Paratuberculose em ruminantes no Brasil ${ }^{1}$
}

\author{
Elise M. Yamasaki²*, Marilene F. Brito ${ }^{3}$, Rinaldo A. Mota ${ }^{4}$, Douglas McIntosh ${ }^{5}$ \\ e Carlos H. Tokarnia ${ }^{6}$
}

\begin{abstract}
Yamasaki E.M., Brito M.F., Mota R.A., McIntosh D. \& Tokarnia C.H. 2013. [Paratuberculosis in ruminants in Brasil: a review.] Paratuberculose em ruminantes no Brasil. Pesquisa Veterinária Brasileira 33(2):127-140. Curso de Pós-Graduação em Ciências Veterinárias, Universidade Federal Rural do Rio de Janeiro, Seropédica, RJ 23890-000, Brazil. E-mail: elise_my@yahoo.com.br

Paratuberculosis also known as Johne's disease, is a granulomatous enteritis caused by Mycobacterium avium subsp. paratuberculosis (MAP), an acid-fast bacillus that preferentially resides within host intestinal macrophages. The condition is most commonly seen in domestic ruminants, however MAP can also infect other mammalian species. Paratuberculosis shows a global distribution and is considered endemic in some regions. The World Organization for Animal Health (OIE, Office International des Epizooties), have classified paratuberculosis as a notificable disease; considered to be of socio-economic and/or public-health importance, the control of which is necessary for the international trade of animal and animal products. The importance of paratuberculosis is related primarily to economic losses in the animal industry and also because of a potential role for this bacterium in the pathogenesis of Crohn's disease, a debilitating condition affecting the digestive tract of humans. In Brazil, paratuberculosis has been reported in a variety of ruminant species and shows a broad geographic distribution. The reported incidence of natural cases in Brazil has been limited, but it is believed that interespecific transmission of MAP and dissemination of the agent is driven by the commercialization of infected animals. The main objective of this paper was to collate the published epidemiological, clinic-pathological and diagnostic information in relation to paratuberculosis in cattle, buffaloes, goats and sheep in Brazil. Moreover, it served as a platform to emphasize the requirement to implement sanitary policies for control of MAP in the county, which may serve to improve the quality and value of animal products on international markets.
\end{abstract}

INDEX TERMS: Paratuberculosis, Johne's disease, cattle, buffaloes, sheep, goats, Brazil.

RESUMO.- A paratuberculose ou doença de Johne é uma enterite granulomatosa causada por Mycobacterium avium subsp. paratuberculosis (Map) e comumente afeta rumi-

\footnotetext{
${ }^{1}$ Recebido em 19 de setembro de 2012.

Aceito para publicação em 26 de novembro de 2012.

${ }^{2}$ Doutoranda no Curso de Pós-Graduação em Ciências Veterinárias, Área de Concentração em Sanidade Animal, Universidade Federal do Rio de Janeiro (UFRRJ), Rodovia BR 465 Km 7, Seropédica, RJ 23890-000, Brasil. *Autor para correspondência: elise_my@yahoo.com.br

${ }^{3}$ Departamento de Epidemiologia e Saúde Pública, Instituto de Veterinária, UFRRJ, Seropédica, RJ 23890-000.

${ }^{4}$ Departamento de Medicina Veterinária, Universidade Federal Rural de Pernambuco (UFRPE), Rua Dom Manoel de Medeiros s/n, Dois Irmãos, Recife, PE 52171-900, Brasil.

5 Departamento de Parasitologia Animal, Instituto de Veterinária, UFRRJ, Seropédica, RJ.

${ }^{6}$ Departamento de Nutrição Animal e Pastagem, Instituto de Zootecnia, UFRRJ, Seropédica, RJ.
}

nantes domésticos, no entanto, pode infectar várias espécies de mamíferos. Está presente nos cinco continentes e é considerada endêmica em algumas regiões pela Organização Internacional de Epizootias (OIE). Pertence à lista de enfermidades notificáveis, que compreende as doenças transmissíveis de importância sócio-econômica e/ou em saúde-pública, cujo controle é necessário para o comércio internacional de animais e alimentos de origem animal. A importância da doença de Johne não se restringe somente aos prejuízos econômicos causados à indústria animal, mas também na possível participação do Map na íleocolite granulomatosa que afeta seres humanos, conhecida como doença de Crohn. No Brasil, a paratuberculose já foi descrita em diversas espécies de ruminantes e em vários estados. Embora os relatos naturais da enfermidade sejam pontuais, acredita-se na possibilidade da transmissão interespecífica e na disseminação do agente através da compra e venda 
de animais infectados. 0 objetivo deste artigo foi reunir as informações disponíveis referentes aos aspectos epidemiológicos, clínico-patológicos e laboratoriais da paratuberculose em bovinos, bubalinos, caprinos e ovinos no Brasil, e salientar a necessidade de implementação de medidas de controle sanitário da enfermidade no país, o que possibilitaria a melhoria da qualidade e valorização dos produtos de origem animal no mercado internacional.

TERMOS DE INDEXAÇÃO: Paratuberculose, bovinos, búfalos, ovinos, caprinos, Brasil.

\section{INTRODUÇÃO}

A doença de Johne está presente nos cinco continentes e é considerada uma doença transmissível de importância sócio-econômica e/ou em saúde-pública, cujo controle é necessário para o comércio internacional de animais e alimentos de origem animal (OIE 2012). Os mecanismos de persistência e virulência do Map não estão completamente elucidadas, mas, assim como outras micobactérias patogênicas, o Map mostra resistência à destruição pelos macrófagos através da inibição da conversão de fagossomos a fagolisossomos (Jubb et al. 2007, Coussens et al. 2010). Comumente afeta ruminantes domésticos, no entanto, pode infectar várias espécies de mamíferos (Clarke 1997, OIE 2012).

Os prejuízos econômicos causados pela paratuberculose ocorrem, principalmente, em rebanhos leiteiros e estão relacionados à diminuição da produção de leite, no ganho de peso, baixa eficiência reprodutiva, abate prematuro e redução do valor da carcaça ao abate (Hendrick et al. 2005, OIE 2012) e é considerada uma potencial ameaça à indústria animal devido à sua natureza insidiosa (OIE 2012). 0 impacto econômico global que a enfermidade causa na produção animal não está claramente definido, no entanto, nos EUA, por exemplo, estima-se que as perdas anuais cheguem a 250 milhões de dólares (Losinger 2005).

A importância da doença de Johne na saúde pública se deve a sua possível associação com a doença de Crohn (Crohn et al. 1932, Hermon-Taylor 2001, Grant 2005, Okura et al. 2012). Neste contexto, pesquisadores têm relatado a presença de Map no leite cru e pasteurizado (Grant et al. 2002, Ayele et al. 2005, Slana et al. 2009, Okura et al. 2012); além disso, a micobactéria foi detectada no sangue de pacientes com a doença de Crohn (Naser et al. 2004). Esta possível relação com a enterite em seres humanos é polêmica, e ainda são necessários estudos epidemiológicos amplos, com a utilização de modernas técnicas moleculares para desvendar a real causa da doença de Crohn e determinar se o Map tem significado etiológico primário ou se é apenas um invasor secundário (Collins et al. 2000, Naser et al. 2004, Austschbach et al. 2005, Singh et al. 2010, Momotani et al. 2012). Até o momento, a paratuberculose não é considerada uma zoonose (OIE 2012).

No Brasil, estudos realizados nos últimos 97 anos, demonstraram que a enfermidade está presente em várias regiões do país: Dupont 1915, Santos \& Silva 1956, Dacorso Filho et al. 1960, Silva \& Pizelli 1961, Portugal et al. 1979, Riveira 1996, Driemeier et al. 1999, Fonseca et al. 2000,
Ferreira et al. 2001, Gomes et al. 2002, Acypreste et al. 2005, Mota et al. 2007, Ristow et al. 2007, Dib et al. 2008, Mota et al. 2010, Yamasaki et al. 2010, Dalto et al. 2012, entre outros (Quadro 1) e os prejuízos econômicos associados com Map estão provavelmente subestimados. Nota-se a crescente importância da paratuberculose no Brasil não só em bovinos, mas também em bubalinos (Barbosa et al. 2010, Mota et al. 2010, Dalto et al. 2012), ovinos e caprinos (Jacintho et al. 2009, Oliveira et al. 2010, Medeiros et al. 2012a). Sendo detentor do maior rebanho comercial de bovinos do mundo, o Brasil precisa colocar no mercado produtos de origem animal de qualidade e de baixo risco sanitário para consumidores internos cada vez mais exigentes (PNCEBT 2006). Por este motivo, o objetivo deste artigo foi reunir as informações disponíveis na literatura, referentes aos aspectos epidemiológicos, clínico-patológicos e laboratoriais da paratuberculose em bovinos, bubalinos, caprinos e ovinos no Brasil e, salientar a necessidade de implementação de medidas de controle sanitário da enfermidade no país, fato que possibilitaria a melhoria da qualidade e valorização dos produtos de origem animal no mercado internacional.

\section{BREVE HISTÓRICO DA PARATUBERCULOSE}

A paratuberculose foi descrita pela primeira vez na Alemanha, em 1895, por Johne e Frothingam como uma forma atípica da tuberculose em uma vaca com seis anos de idade, que apresentava perda de peso e diarreia crônica (Johne \& Frothigam 1895). À necropsia, os autores observaram enterite sem lesões compatíveis com tuberculose intestinal, apesar de a histopatologia revelar infiltração granulomatosa e BAARs. No início foi proposto o nome de enterite pseudotuberculosa, e posteriormente foi modificado para paratuberculose, ao constatarem que se tratava de uma bactéria diferente daquela causadora da tuberculose. Anos mais tarde, foi também denominada de doença de Johne. Apenas em 1910 o microrganismo foi isolado em meio de cultivo e caracterizado como Mycobacterium enteritidis chronicae pseudotuberculosae bovis Johne (Twort \& Ingram 1912). Após pesquisas, estudiosos o denominaram de Mycobacterium johnei e Mycobacterium paratuberculosis e, apenas em 1990 recebeu a denominação taxonômica de Mycobacterium avium subsp. paratuberculosis (Thorel et al. 1990), aceita até hoje.

\section{A PARATUBERCULOSE NO BRASIL}

No Brasil, a doença de Johne foi relatada pela primeira vez, no ano de 1915, no Jornal do Commércio, em bovinos da raça Flamenga importados da Bélgica, no então Posto Zootécnico Federal de Pinheiro, no estado do Rio de Janeiro, pelo Professor Otávio Dupont (Dupont 1915). Atualmente há descrições da enfermidade em vários estados do país e em diversas espécies de ruminantes; estudos demonstraram que a paratuberculose está presente em 11 estados brasileiros em bovinos, búfalos, ovinos e caprinos (Quadro 1) e sugerem que a enfermidade foi introduzida no território nacional através da importação de animais infectados. As primeiras evidências da enfermidade ocorreram em bo- 
Quadro 1. Histórico da paratuberculose no Brasil

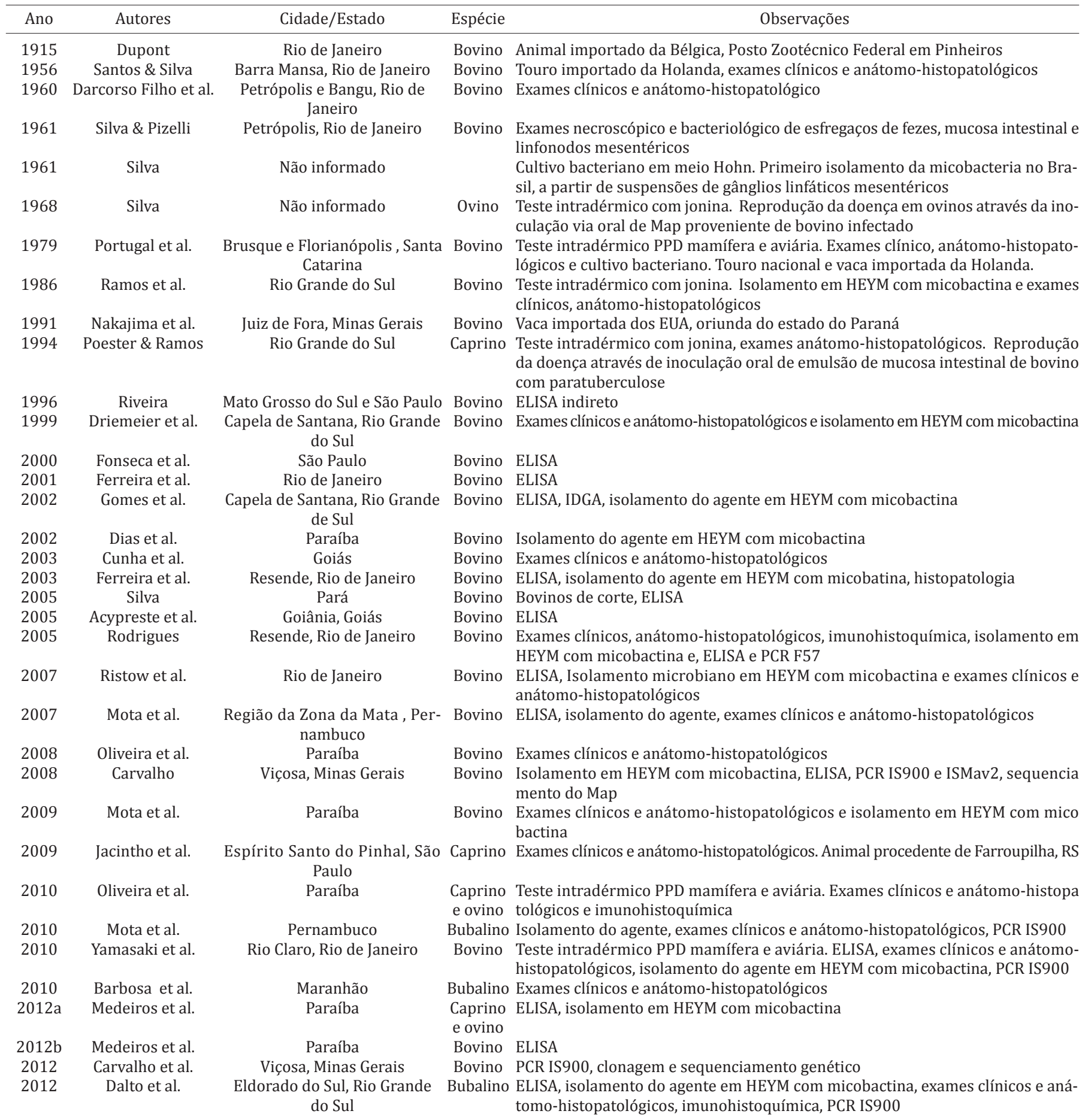

vinos importados da Bélgica (Dupont, 1915), da Holanda (Santos e Silva 1956, Portugal et al. 1979), em cria de vaca trazida da Holanda (Dacorso Filho et al. 1960) e mais recentemente, em animais oriundos da Argentina (Driemeier et al. 1999).

Entre o primeiro caso descrito da doença de Johne no Brasil, no ano de 1915 até meados dos anos 90, o diagnóstico foi baseado em achados clínicos e anátomo-histopatológicos com a demonstração de BAARs e ou isolamento do Map em meio de cultivo. As estimativas de prevalên- cia, tanto em nível individual quanto de rebanho, são realizadas de acordo com a importância da enfermidade em diversos setores, como por exemplo, na economia, na produção animal e ou na saúde pública. 0 planejamento das medidas sanitárias requer objetivos diferentes conforme a necessidade que cada região geográfica apresenta em relação à incidência da enfermidade estudada, ou seja, medidas voltadas para a erradicação da enfermidade em áreas com baixa prevalência de animais infectados, ou para o controle em áreas com alta prevalência ou ainda, para o aumento 
da vigilângia em locais em que a enfermidade encontra-se ausente. Desta forma, a obtenção de dados sobre a prevalência de animais infectados exige testes laboratoriais com sensibilidade e especificidade confiáveis. Neste contexto, é interessante salientar que, apesar do advento de modernas técnicas imunológicas e moleculares de diagnóstico da paratuberculose, o cultivo bacteriano ainda é considerado o método "gold standard" para o diagnóstico definitivo da paratuberculose ou para a validação de novos testes (Timms et al. 2011), e isto pode estar relacionado às diversas peculiaridades associados ao patógeno e à resposta imunológica do hospedeiro frente à infecção.

\section{EPIDEMIOLOGIA}

Os aspectos epidemiológicos da paratuberculose têm sido amplamente descritos em vários países; o Map afeta principalmente bovinos e também foi descrita em ovinos, caprinos, bubalinos, ruminantes silvestres e em outras espécies de mamíferos (Behr \& Collins 2010, OIE 2012). Criações leiteiras são as mais afetadas, pois o confinamento oferece condições para a propagação da infecção entre os indivíduos (Nielsen \& Toft, 2008).

Nos casos descritos da enfermidade no Brasil, em geral, estão relatados os achados clínico-patológicos e aspectos do diagnóstico laboratorial, porém, as informações epidemiológicas não estão detalhadamente apresentadas. A partir das informações disponíveis, nota-se que bovinos leiteiros são os mais afetados; há descrições nesta espécie nas cinco regiões do país: na região nordeste, nos estados de Pernambuco (Mota et al. 2007) e Paraíba (Oliveira et al. 2008, Mota et al. 2009); na região sudeste nos estados do Rio de Janeiro (Dupont 1915, Santos e Silva 1956, Dacorso et al. 1960, Silva \& Pizelli 1961, Ferreira et al. 2003, Ristow et al. 2007, Yamasaki et al. 2010 ), São Paulo (Fonseca et al. 2000) e Minas Gerais (Nakajima et al. 1991, Carvalho 2008); na região Sul, em Santa Catarina (Portugal et al. 1979), Rio Grande do Sul (Ramos et al. 1986, Driemeier et al. 1999, Gomes et al. 2002); na região centroeste, nos estados de Mato Grosso do Sul (Riveira 1996) e Goiás (Cunha et al. 2003, Acypreste et al. 2005) e na região norte, no estado do Pará (Silva 2005). Na espécie bubalina, apesar de ser considerado menos susceptível à infecção pelo Map em relação aos bovinos (Sivakumar et al. 2006), foram relatados, até o momento, casos clínicos de paratuberculose em duas regiões do país; o primeiro caso foi descrito na região nordeste, estado de Pernambuco por Mota et al. (2010), em seguida por Barbosa et al. (2010) no estado de Maranhão. Posteriormente, Dalto et al. (2012) relataram um rebanho bubalino infectado por Map na região Sul, no estado do Rio Grande do Sul. Até o momento, a ocorrência da doença de Johne em pequenos ruminantes no país, foi descrita em apenas duas regiões brasileiras; na região sudeste, especificamente no estado de São Paulo (Jacintho et al. 2009) e na região nordeste, no estado da Paraíba em caprino e ovino (Oliveira et al. 2010, Medeiros et al. 2012a). Portanto, atualmente no Brasil, há relatos de casos naturais da paratuberculose em grandes e pequenos ruminantes nascidos e criados no território nacional, diagnosticados por aspectos clínico-patológicos e confirmados por testes laboratoriais específicos (Quadro 1).
A principal via de infecção é a oro-fecal nos primeiros meses de vida do animal, no momento da ingestão de colostro ou leite e quando entram em contato com o úbere contaminado com fezes contendo a micobactéria (Begg \& Whittington 2008). No Brasil, Dalto et al. (2012) relataram que bezerros do rebanho de bubalinos estudado, eram criados no sistema de aleitamento natural diretamente do úbere e vários bezerros mamavam coletivamente nas fêmeas lactantes, esta condição pode favorecer os índices de soropositivos no rebanho. Existem também, evidências de infecção intrauterina de bovinos e ovinos em estágio avançado da doença, quando a fêmea gestante é portadora de grande quantidade de microrganismos e a anergia permite a migração de macrófagos infectados para outros órgãos através do sistema linfático (Chiodini et al. 1984a, Buergelt et al. 2006, Whittington \& Windsor 2009). Silva (1961) relatou a observação de BAARs em baço de feto de vaca com sinais clínicos da enfermidade no país; nestes casos a micobactéria pode ser isolada em meio de cultivo através do colostro e do leite (Pithua et al. 2011).

O lento desenvolvimento da doença de Johne e a subsequente imperceptível e prolongada transição entre os estágios da infecção, dificultam a detecção de todos os animais infectados no rebanho (Behr \& Collins 2010). Os dados sobre a prevalência mundial da paratuberculose variam notavelmente de acordo com a metodologia utilizada no estudo (isolamento bacteriano, sorologia, técnicas de biologia molecular) e o tipo de amostra analisada (Nielsen \& Toft, 2008, Behr \& Collins 2010, Timms et al. 2011, OIE 2012). Estima-se que cerca de 30 a $50 \%$ do rebanho mundial está infectado (Behr \& Collins 2010). Em um rebanho bovino infectado, em média, 10\% dos animais desenvolvem a doença, o restante, em sua maioria, eliminam o agente através das fezes, sem apresentar os sinais clínicos ao longo de sua vida. A manifestação clínica pode estar relacionada a diversos fatores, tais como, ingestão de diferentes doses infectantes de Map, susceptibilidade individual à infecção e idade em que o animal teve o primeiro contato com o Map (Nielsen \& Toft 2008). Em um rebanho, geralmente a mortalidade é menor que $1 \%$ ao ano e estima-se que até $70 \%$ dos animais podem estar infectados (Timms et al. 2011). Animais com diarreia eliminam maior quantidade de Map em comparação com indivíduos assintomáticos, que pode ocorrer em qualquer fase da infecção, além disso, a bactéria é raramente detectada antes dos dois anos de idade (Clarke 1997, Behr \& Collins 2010, Timms et al. 2011).

A transmissão para animais adultos é pouco comum, pois são mais resistentes à infecção; porém, alguns pesquisadores reproduziram a doença em indivíduos desta faixa etária através da administração de diferentes doses de Map (Kurade et al. 2004, Clarke et al. 2010, Clarke et al. 2011). A possibilidade de infecção entre as espécies também foi constatada experimentalmente no Brasil, por Silva (1968) e Poester \& Ramos (1994) respectivamente, em ovinos e caprinos, os quais desenvolveram a patologia após administração via oral, de emulsão de intestino e linfonodo mesentérico de bovino com paratuberculose clínica. No entanto, estudos comparativos revelaram que isolados de Map de ovinos e de bovinos possuem características moleculares 
diferentes (Whittington et al. 2001, Collins et al. 2002), este achado apresenta uma implicação epidemiológica importante nas propriedades em que as duas espécies são criadas na mesma pastagem e, portanto, a infecção entre ovinos e bovinos pode ser bem menos frequente (Douarre et al. 2012). A identificação de diferentes cepas de microrganismos é uma ferramenta valiosa em investigações epidemiológicas (Kaur et al. 2011), e possibilita determinar, por exemplo, a fonte de infecção, os fatores de risco que influenciam na transmissão do patógeno, se a infecção é resultado da introdução de um animal proveniente de outro rebanho ou se está associada ao contato com o ambiente contaminado da propriedade. Isto facilita a avaliação de programas de controle regionais e adoção de medidas sanitárias estratégicas, direcionado para cada rebanho (Motiwala et al. 2006). 0 entendimento da diversidade genômica entre as cepas de Map também pode fornecer "insights" na compreensão dos mecanismos de especificidade de hospedeiro em associação com genótipos específicos (Motiwala et al. 2006), tanto nos casos clínicos quanto nos subclínicos.

\section{PATOGÊNESE E IMUNIDADE DO HOSPEDEIRO}

Após a ingestão, o Map é fagocitado pelas células M, que têm a função de recobrir as placas de Peyer e transportar antígenos da barreira epitelial do lúmem intestinal para o tecido linfoide. As células M são a via de infecção para alguns patógenos e porta de entrada do antígeno para iniciar as respostas imunológicas de proteção (Momotani et al. 1988, Coussens et al. 2010, Fukuda et al. 2011). Uma vez dentro de macrófagos, o patógeno persiste e se multiplica no interior do fagossomo; à semelhança do M. tuberculosis, a capacidade de se manter no ambiente intracelular se deve à habilidade da micobactéria em bloquear a fusão do fagossomo com o lisossomo (Gatfield \& Pieters 2003, Rohde et al. 2007).

A imaturidade dos macrófagos em animais jovens pode ser uma das causas da susceptibilidade à infecção dos animais jovens (Momotani et al. 1988). A tentativa dos macrófagos em conter, sem sucesso, a multiplicação intracelular dos bacilos, resulta na liberação de fatores solúveis, os quais recrutam novas células inflamatórias para o local. 0 efeito da invasão tecidual pelos bacilos é a multiplicação dos macrófagos e consequente formação atípica de granulomas nos segmentos mediano e distal do intestino delgado, característica da doença de Johne (Tiwari et al. 2006, Coussens et al. 2010). Além disso, o Map não produz toxinas ou fatores de virulência e não causa danos celulares, células gigantes se formam como parte da reação de hipersensibilidade tardia e o resultado é o espessamento do tecido intestinal pelo acúmulo das células inflamatórias, o que pode comprometer a absorção de nutrientes, a vascularização e a drenagem linfática (Chiodini et al. 1984b, Coussens et al. 2010).

Como em outras micobacterioses, tais como lepra e tuberculose, a paratuberculose é considerada uma doença dinâmica em que há períodos de flutuações da imunidade celular ou períodos em que ocorre resposta humoral quando o hospedeiro perde resistência frente ao agente. A doença é o reflexo da reação imune do hospedeiro e, durante o curso da infecção, há períodos de remissão e exacerbação da atividade imunológica (Stabel 2010). Na fase terminal, a anergia permite que macrófagos infectados alcancem a corrente circulatória, o que provoca a bacteremia e disseminação do microrganismo para o fígado, rins, pulmões, trato reprodutor e úbere (Clarke 1997, Coussens et al. 2010).

A imunidade específica contra micobactérias é essencialmente mediada por células; os anticorpos possuem eficácia limitada contra estes agentes e a sua destruição está principalmente relacionada a mecanismos intracelulares de eliminação através de macrófagos infectados (Stabel 2010). As respostas imunológicas não são bem conhecidas; no início da infecção há uma resposta celular e após a progressão da infecção, já na fase clínica observa-se uma resposta humoral, desencadeada pela liberação de bacilos presentes no citoplasma de macrófagos que se rompem. Neste estágio, geralmente, observa-se uma relação inversa entre a imunidade celular e humoral e, no final, ocorre a anergia, fase em que não é possível detectar nem a imunidade celular nem a imunidade humoral (Chiodini et al. 1984b, Stabel, 2010).

\section{ASPECTOS CLÍNICOS}

\section{Bovinos e búfalos}

A sintomatologia típica da paratuberculose ocorre em animais a partir de dois anos de idade; a partir desta idade, a doença progride para a fase terminal e resulta em morte do animal. Caracteriza-se por perda progressiva de peso, apesar dos animais apresentarem apetite normal ou mesmo exacerbado, desidratação, diarreia intermitente, profusa, homogênea, semifluida ou líquida, não responsiva a tratamentos e que, progressivamente, torna-se contínua e a eliminação das fezes ocorre sob forma de jato (Clarke 1997, Jubb et al. 2007, Behr \& Collins 2010). Este quadro foi observado em bovinos e búfalos em diversas regiões do país (Dacorso-Filho et al. 1960, Portugal et al. 1979, Driemeier et al. 1999, Ristow et al. 2006, Mota et al. 2007, Carvalho 2008, Oliveira et al. 2008, Yamasaki et al. 2010, Barbosa et al. 2010, Dalto et al. 2012), os quais, após exame necroscópico, apresentaram lesões compatíveis com a enfermidade.

0 acentuado acúmulo de células inflamatórias, principalmente na mucosa e submucosa intestinal, desencadeia a chamada síndrome da má absorção, o que diminui a assimilação de nutrientes, reduz a eficiência produtiva e causa o declínio da condição corporal (Chiodini et al. 1984, Clarke 1997). Normalmente, a manifestação clínica da paratuberculose está associada com eventos de estresse como partos, deficiência nutricional e produção de leite elevada (Clarke 1997). A ocorrência de doenças intercorrentes foi descrita no Brasil, em que os animais estudados apresentaram mastite e problemas reprodutivos e morreram após cerca de quatro meses após o início dos sinais clínicos (Mota et al. 2010, Yamasaki et al. 2010, Dalto et al. 2012), inclusive tuberculose foi relatado (Driemeier et al. 1999).

\section{Ovinos e caprinos}

Em pequenos ruminantes, há maior dificuldade em se diagnosticar a paratuberculose através dos aspectos clínicos, pois a sintomatologia quando presente é inespecífica. 
Em geral os animais não apresentam diarreia; podem ser observados emagrecimento progressivo, emaciação nos estágios adiantados da infecção e fezes pastosas (Clarke 1997, Kruze et al. 2006, Jubb et al. 2007, McGavin \& Zachary 2007, Robbe-Austerman 2011). No Brasil, o quadro clínico sugestivo da enfermidade foi descrito em caprino por Jacintho et al. (2009) no estado de São Paulo, que apresentou emagrecimento lento, fezes amolecidas, tosse e dificuldade respiratória. Igualmente, Oliveira et al. (2010) relataram dispneia e tosse em caprino infectado com Map, no estado da Paraíba, além disso, foi observado caquexia, desidratação, edema submandibular, arritmia cardíaca, áreas de alopecia com formação de crostas, pelos ásperos e quebradiços e, inclusive, apetite exacerbado. Ainda, os autores relataram que um ovino também apresentou caquexia, fezes pastosas, áreas de alopecia bilateral na região toracolombar, alterações estas que se manifestaram após o parto. À necropsia os animais apresentaram lesões sugestivas de doença de Johne, que foram confirmados por testes laboratoriais.

\section{ASPECTOS ANÁTOMO-HISTOPATOLÓGICOS Macroscopia}

Bovinos e búfalos. Lesões macroscópicas estão presentes apenas na fase adiantada da infecção; observam-se à necropsia, vasos linfáticos subserosos intestinais proeminentes, esbranquiçados e com aspecto varicoso, que podem se estender até o mesentério. A linfangite é um achado importante e é específico o suficiente para justificar o diagnóstico da paratuberculose à necropsia (Jubb et al. 2007). Lesões mais específicas ocorrem no intestino delgado que, nos casos mais graves, se estendem desde o duodeno até o reto; caracterizam-se por espessamento da parede intestinal, em que a serosa adquire aspecto cerebroide e/ou anelado devido à formação de rugas e pregas transversais na mucosa e aspecto microgranular em sua superfície. Os linfonodos mesentéricos encontram-se edematosos, aumentados de tamanho e ao corte, protrui e flui grande quantidade de líquido leitoso (Clarke 1997, Jubb et al. 2007). As lesões macroscópicas descritas foram observadas por diversos autores nacionais em bovinos (Santos \& Silva 1956, Dacorso-Filho et al. 1960, Silva \& Pizelli 1961, Portugal et al. 1979, Driemeier et al. 1999, Cunha et al. 2003, Ristow et al. 2006, Mota et al. 2007, Oliveira et al. 2008, Mota et al. 2009, Yamasaki et al. 2010) e bubalinos (Barbosa et al. 2010, Mota et al. 2010, Dalto et al. 2012). Adicionalmente, alguns autores observaram mineralização das grandes artérias com a íntima dos vasos enrrugada, esbranquiçada com aspecto opaco e confirmados ao exame histopatológico em bovinos (Driemeier et al. 1999, Cunha et al. 2003, Yamasaki et al. 2010) e também em bubalinos (Dalto et al. 2012).

Ovinos e caprinos. Lesões macroscópicas da paratuberculose nos pequenos ruminantes ocorrem com menor intensidade em relação aos bovinos e nem sempre estão visíveis; quando estão presentes pode-se observar parede intestinal espessada e enrugada, mucosa intestinal com aspecto granular sem ulcerações e aumento dos linfonodos mesentéricos (Clarke 1997, Jubb et al. 2007). No entanto, no Brasil, Oliveira et al. (2010), relataram que ovinos infectados região nordeste do Brasil, apresentaram úlceras multifocais na mucosa de intestino delgado e cólon. Clarke (1997) relatou que pequenos ruminantes com sinais clínicos severos da paratuberculose podem não apresentar alterações macroscópicas, o que foi constatado também por alguns autores brasileiros (Jacintho et al. 2009, Oliveira et al. 2010). Adicionalmente, podem-se notar tubérculos caseificados e, eventualmente, calcificados na mucosa, submucosa, serosa do intestino e de linfonodos, ou ainda, a presença de pequenos nódulos esbranquiçados que evoluem para a caseificação e mineralização (Clarke 1997). À semelhança, nódulos esbranquiçados na serosa intestinal foram descritos em ovinos, por Oliveira et al. (2010). Os linfonodos de outras regiões do organismo podem conter lesões granulomatosas focais mineralizadas ou não (Clarke 1997, Behr \& Collins 2010). Uma característica particular é a coloração laranja-amarelada observada na mucosa do intestino de pequenos ruminantes infectados, causada por cepas pigmentadas de Map (Clarke \& Little 1996, Sevilla et al. 2007, Behr \& Collins 2010), igualmente relatado por Oliveira et al. (2010), que observaram mucosa intestinal e linfonodo mesentérico com pigmentação de coloração amarelo-marrom em ovino com sinais clínicos da paratuberculose.

\section{Histopatologia}

Bovinos e búfalos. Há duas classificações da doença de Johne em animais com sinais clínicos da enfermidade: forma tuberculoide ou "paucibacillary", no qual o infiltrado inflamatório, principalmente na mucosa e submucosa do intestino delgado, é composto de linfócitos e alguns macrófagos contendo poucas micobactérias, que está relacionada à marcada resposta imune celular e corresponde ao início ou à fase latente da infecção. Na forma lepromatosa ou "multibacillary" há intensa infiltração granulomatosa com formação de células gigantes de Langhans que contém inúmeros BAARs na mucosa e submucosa do intestino delgado e grosso e, está associada à forte resposta humoral (Chiodini et al. 1984b, Pérez et al. 1996, Clarke 1997, Corpa et al. 2000). As vilosidades apresentam-se espessadas e atrofiadas dependendo do estágio da infecção. Observam-se ainda, proliferação fibroblástica ao redor dos plexos nervosos de Meissner e de Auerbach, linfangiectasia e linfangite granulomatosa na subserosa. As secções dos linfonodos mesentéricos apresentam, igualmente, lesões de natureza granulomatosa, na zona cortical, paracortical e medular, e presença de BAARs. A forma "multibacillary" foi descrita por vários autores brasileiros em bovinos (Dacorso-Filho et al. 1960, Portugal et al. 1979, Ramos et al. 1986, Driemeier et al. 1999, Cunha et al. 2003, Ristow et al. 2006, Mota et al. 2007, Oliveira et al. 2008, Mota et al. 2009, Barbosa et al. 2010, Yamasaki et al. 2010) e em bubalinos (Mota et al. 2010, Barbosa et al. 2010, Dalto et al. 2012), nas regiões sudeste, sul e nordeste do país. Presença de granulomas no parênquima hepático também foram decritos tanto nos bovinos (Driemeier et al. 1999, Cunha et al. 2003, Yamasaki et al. 2010) quanto nos bubalinos (Dalto et al. 2012). Além da histopatologia de tecidos coletados à necropsia, Dalto et 
al. (2012) relataram que a biópsia retal pode ser mais uma ferramenta para confirmação do diagnóstico de paratuberculose em búfalos; nos fragmentos analisados pelos autores, haviam BAARs e ao teste de imunoistoquímica, foram positivos para detecção de Mycobacterium avium.

\section{Imuno-histoquímica}

O teste de imunoistoquímica (IHQ) tem sido utilizado por diversos pesquisadores no intuito de confirmar a infecção por Map, tanto em animais quanto em pacientes humanos com doença inflamatória intestinal (Kobayashi et al. 1989, Pierce et al. 2009, Oliveira et al. 2010, Dalto et al. 2012, Momotani et al. 2012). No Brasil, estudiosos têm empregado esta metodologia para confirmação da paratuberculose (Rodrigues 2005, Oliveira et al. 2010, Dalto et al. 2012). Uma das vantagens da IHQ está relacionada à elevada sensibilidade em relação à técnica de Ziehl Neelsen e "in situ hibridization" (Paolicchi et al. 2001, Delgado et al. 2009) para detecção de Map, o que confere a maior acurácia ao teste, principalmente, em casos contendo poucas micobactérias. A presença "in situ" do agente infeccioso e ou antígeno pesquisado, proporciona maior confiabilidade ao teste, minimiza as possibilidades de diagnóstico falso-positivo devido às imunorreações inespecíficas e pode auxiliar na compreensão da patogênese (Brees et al. 2000, Dabbs 2010, Webster et al. 2010). Além disso, proteínas recombinantes têm sido desenvolvidas para produção de anticorpos espécie específicos contra Map para utilização em testes de imunofluorescência, imunoistoquímica e western-blotting (Souza et al. 2012).

Ovinos e Caprinos. Em pequenos ruminantes, a infiltração inflamatória na lâmina própria da mucosa intestinal é formada principalmente por linfócitos e as lesões são consistentes com a forma tuberculoide da infecção (Khodakaram-Tafti \& Rashidi 2000, Kruze et al. 2006). No Brasil, Oliveira et al. (2010) observaram infiltração inflamatória, predominantemente por macrófagos e poucos linfócitos e plasmócitos em caprinos e ovinos com sinais clínicos da paratuberculose, no entanto, outros indivíduos destas mesmas espécies, sem a manifestação clínica, apresentaram infiltração predominantemente linfocítica. Adicionalmente, Jacintho et al. (2009) observaram área focal de necrose na submucosa intestinal, associado ao infiltrado supurativo e granulomatoso.

A classificação das lesões histológicas da paratuberculose clínica e subclínica em ovinos desenvolvido por Pérez et al. (1996) foi utilizada por Oliveira et al. (2010) em um caprino e um ovino com a forma clínica da enfermidade, que apresentou lesão multibacilar difusa (Corpa et al. 2000) e lesão lepromatosa (Pérez et al. 1996), respectivamente. Na classificação proposta por Pérez et al. (1996) observam-se acentuada lesão macroscópica e histológica, similares às descrições dos casos clínicos de outros autores (Clarke \& Little 1996, Kheirandish et al. 2008); há numerosos macrófagos e poucas células gigantes distribuídas difusamente na lâmina própria e submucosa intestinal, fusão dos vilos e espessamento do intestino. Podem ser observados BAARs nos macrófagos da lâmina própria, e em menor quantidade nos tecidos linfoides do intestino e linfonodos. Oliveira et al. (2010) relatam ainda, que outros indivíduos, com a forma subclínica apresentaram enterite linfocítica difusa (Pérez et al. 1996, Corpa et al. 2000).

A presença de granulomas periportais e em regiões do parênquima hepático em pequenos ruminantes, tanto nas lesões lepromatosas quanto nas tuberculoides foram descritos por Clarke \& Little (1996), lesões observadas também por autores brasileiros (Jacintho et al. 2009, Oliveira et al. 2010).

\section{MÉTODOS DE DIAGNÓSTICO}

\section{Cultivo bacteriano}

Mycobacterium avium subsp. paratuberculosis é uma micobactéria cultivável que apresenta crescimento lento, com tempo de duplicação in vitro entre 22 e 26 horas (Bannantine et al. 2003). Sob condições ótimas, são necessárias, aproximadamente, 16 semanas para se formarem colonias visíveis (OIE 2012). 0 sucesso do isolamento do Map depende de vários fatores, como a composição do meio de cultura, a natureza da amostra clínica (sangue, fezes, leite, tecidos), o uso ou não de um protocolo de descontaminação, o estágio (recente ou avançado) e a forma (clínica ou subclínica) da infecção (Timms et al. 2011). Apesar de o cultivo bacteriano ser considerado pela OIE, o teste "gold standard", a sensibilidade varia entre $50 \%$ e $70 \%$, quando o isolamento é feito a partir de amostras fecais de bovinos (Stabel 1997, Collins et al. 2006, Timms et al. 2011), desta forma, as taxas de prevalência podem estar subestimadas quando determinadas por esta técnica. Os meios de cultivo comumente utilizados para o isolamento de Map são Herrold egg yolk medium (HEYM), meio de Dubbos modificado, Middlebrook e Löwenstein-Jensen acrescidos de micobactina (Klanikova et al. 2012, OIE 2012).

No Brasil, os primeiros estudos realizados para o isolamento do agente, utilizaram o meio de cultura Hohn com glicerina (Silva 1961) e meio de Petragnani (Portugal et al. 1979). A partir da década de 80, pesquisadores começaram o utilizar o HEYM acrescido de micobactina (Ramos et al. 1986) e atualmente, estudos em todo o país, fazem o uso desta metodologia (Poester \& Ramos 1994, Dias et al. 2002, Gomes et al. 2002, Ferreira et al. 2003, Rodrigues 2005, Mota et al. 2007, Carvalho 2008, Mota et al. 2010, Yamasaki et al. 2010, Dalto et al. 2012, Medeiros et al. 2012a). Os isolamentos de Map foram realizados a partir de amostras de fezes e ou tecidos de bovinos (Silva 1961, Portugal et al. 1979, Ramos et al. 1986, Driemeier et al. 1999, Dias et al. 2002, Gomes et al. 2002, Ferreira et al. 2003, Rodrigues et al. 2005, Mota et al. 2007, Ristow et al. 2007, Mota et al. 2009, Mota et al. 2010, Yamasaki et al. 2010), bubalinos (Mota et al. 2010, Dalto et al. 2012) e caprino e ovinos (Medeiros et al. 2012a) infectados. Além disso, Carvalho (2008) e Yamasaki et al. (2010) isolaram o patógeno a partir de amostra de leite proveniente, respectivamente, de vaca com sinais clínicos e de amostras coletadas do tanque de armazenamento coletivo. Estudo comparativo realizado por Ristow et al. (2008), revelou que o cultivo bacteriano apresenta $66,6 \%$ de sensibilidade, quando o isolamento é realizado a partir de amostras de fragmentos de intestino. 
Os autores, ainda, correlacionaram os achados patológicos ao cultivo bacteriano, e observaram aumento da sensibilidade do cultivo bacteriano de acordo com o aumento da intensidade das lesões macro e microscópicas.

Apesar de ser considerado o teste "gold standard" (OIE 2012), estudos demonstraram que o cultivo bacteriano é um método impraticável para fins de diagnóstico devido, principalmente, ao prolongado período de tempo necessário para isolamento do agente, frente aos novos testes que conferem maior rapidez, sensibilidade e especificidade nos resultados, tanto para confirmação da infecção quanto para estimar o grau de infecção no rebanho (Behr $\&$ Collins 2010, Timms et al. 2011). Por exemplo, Douarre et al. (2010) compararam a metodologia convencional de cultivo em HEYM e nested-PCR para dois alvos moleculares diferentes, IS900 e ISMAP02, e constataram que a PCR pode produzir resultados rápidos e confiáveis, inclusive, para análise de "pools" de amostras para estimar o "status" da infecção em um rebanho. Igualmente, Aly et al. (2010) utilizaram "pool" de amostras fecais para identificar grupos de vacas que estariam eliminando grande quantidade de Map no ambiente e constataram a eficiência do real-time PCR em comparação ao cultivo bacteriano em HEYM. Desta forma, a rapidez, sensibilidade e especificidade dos testes baseados na PCR torna esta metodologia confiável para a confirmação do diagnóstico rotineiro da paratuberculose.

\section{Diagnóstico imunológico}

Animais infectados desenvolvem tanto a resposta mediada por células quanto a resposta humoral contra Map, no entanto, anticorpos são, geralmente, ausentes durante as fases iniciais da infecção, o que torna necessário o uso de metodologias baseados na detecção da resposta celular (Timms et al. 2011). Existem duas metodologias disponíveis para a detecção da imunidade mediada por células contra a infecção pelo Map: o teste de tuberculina intradérmico, com o uso de jonina ou PPD aviário, e o teste $\gamma$-IFN.

No teste intradérmico avalia-se a reação de hipersensibilidade causada pela resposta imune celular; foi o teste mais utilizado no passado para detecção da infecção precoce pelo Map (Kalis et al. 2003), no entanto, o seu uso é limitado devido à inespecificidade. Testes cervicais comparativos (TCC) com PPD ("protein purified derivative") de origem mamífera e aviária foram avaliados por alguns pesquisadores brasileiros, os quais observaram acentuada reação edematosa no local de inoculação da PPD aviária e ausência de reação à PPD mamífera em bovinos (Portugal et al. 1979, Dib et al. 2008, Yamasaki et al. 2010) e ovino com paratuberculose (Oliveira et al. 2010). Porém, os resultados do TCC devem ser interpretados com cautela, pois, a reação à PPD aviária está associada à exposição ou infecções causadas por diversos agentes do complexo Mycobacterium (M. bovis, M. avium e Map) e por Nocardia farcinius (Lilenbaum et al. 2007). A exposição à micobatérias saprófitas presentes no ambiente, também pode sensibilizar os animais, resultando em reações de hipersensibilidade do tipo tardia inespecífica (Scott et al. 2010). Intradermorreação positiva à Jonina, teste no qual se utiliza PPD de Map, também foi relatada por alguns pesquisadores brasileiros, em ovinos (Silva 1968) e caprinos (Poester \& Ramos 1994) experimentalmente infectados e em infecção natural na espécie bovina (Ramos et al. 1986). Estudos de PPD de Map, na área da proteomica têm sido elaborados, com o intuito de aumentar a sensibilidade dos testes para detecção precoce da infecção (Wynne et al. 2012).

Outro teste baseado na atividade da imunidade celular do hospedeiro é o $\gamma$-IFN, um método imunoenzimático que mensura a produção de $\gamma$-IFN pelas células T sensibilizadas (Jungersen et al. 2002, Coussens 2004) por meio do teste ELISA. Tradicionalmente o antígeno utilizado é o PPD jonina e tem contribuído no estudo da variação da especificidade do teste (Bannantine et al. 2010). Há também descrições de estudos voltados para produção de proteínas recombinantes com o intuito de otimizar a mensuração da resposta celular mediada nas fases iniciais da infecção (Bannantine et al. 2010), condição importante para o planejamento estratégico de medidas de controle e, se conveniente, eliminação precoce dos animais positivos do plantel e, desta forma, minimizar a carga bacteriana no ambiente. No Brasil, até o momento, não há relatos do uso desta metodologia.

\section{Sorologia}

Os testes sorológicos comumente utilizados para detecção da imunidade humoral contra a paratuberculose em ruminantes são fixação de complemento, ELISA (enzyme-linked immunosorbent assay) e imunodifusão em gel de ágar (AGID, Agar gel immunodiffusion) (Singh et al. 2007, Tripathi et al. 2007, OIE 2012), no entanto, nenhum deles é considerado sensível o suficiente para detectar a infecção subclínica (Lilenbaum et al. 2007, OIE 2012). Estudos sorológicos demonstraram que entre 7 e $40 \%$ dos rebanhos distribuídos pelos cinco continentes estão infectados com Map (USDA 2005 apud Timms et al. 2011). A sensibilidade do ELISA é altamente dependente do estágio da infecção; o teste apresenta alta sensibilidade, cerca de $75 \%$, quando a infecção está na fase clínica ou terminal. Em contraste, nos estágios iniciais ou latentes da infecção a sensibilidade é baixa, aproximadamente de 15\% (Collins et al. 2006, Timms et al. 2011).

No Brasil, a partir de 1996, estudos sorológicos da enfermidade foram realizados em rebanhos de grandes e pequenos ruminantes; os dados obtidos apresentaram variação entre 4,7 e 72,22\% de soropositivos ao teste ELISA (Quadro 2). Nestes estudos foram utilizados vários protocolos de ELISA; os autores relataram a utilização de PPA ("protoplasmatic antigen") e testes comerciais oriundos de países livres de tuberculose. É importante salientar que os testes sorológicos para diagnóstico da paratuberculose bovina podem revelar resultados falso positivos, especialmente na presença de tuberculose bovina e aviária (Timms et al. 2011). Além disso, deve-se considerar as possibilidades de reações cruzadas com outros agentes como Escherichia coli (Gilot \& Missone 1994 apud Gomes et al. 2002), Mycobacterium spp, Corynebacterium pseudotuberculosis e Nocardia spp (Yakes et al. 2008, Behr \& Collins 2010), devido à presença de determinantes antigênicos comuns entre os gêneros. Componentes da parede celular especialmente as glicoproteínas e lipoarabinomannan (LAM) têm sido es- 
Quadro 2. Resultados do teste ELISA para detecção da paratuberculose em rebanhos brasileiros

\begin{tabular}{lcccc}
\hline Ano & Autores & Estado & Soropositivos ELISA (\%) & Espécie \\
\hline 1996 & Riveira & Mato Grosso do Sul & 45,5 & Bovinos de corte \\
1996 & Riveira & São Paulo & 65,5 & Bovinos leiteiros \\
2000 & Fonseca et al. & São Paulo & 37,9 & Bovinos leiteiros \\
2001 & Ferreira et al. & Rio de Janeiro & 4,7 a 42,5 & Bovinos leiteiros \\
2002 & Gomes et al. & Rio Grande do Sul & 26 & Bovinos leiteiros \\
2003 & Ferreira et al. & Rio de Janeiro & 11,88 & Bovinos leiteiros \\
2005 & Acypreste et al. & Goiás & 60,24 & Bovinos leiteiros \\
2005 & Silva & Pará & 35,4 & Bovinos de corte \\
2007 & Mota et al. & Pernambuco & 32,3 & Bovinos leiteiros \\
2007 & Ristow et al. & Rio de Janeiro & 12,8 & Bovinos leiteiros \\
2010 & Yamasaki et al. & Rio de Janeiro & 40 & Bovinos leiteiros \\
$2012 \mathrm{a}$ & Medeiros et al. & Paraíba & 44,86 & Caprinos \\
$2012 \mathrm{a}$ & Medeiros et al. & Paraíba & 52,96 & Ovinos \\
$2012 \mathrm{~b}$ & Medeiros et al. & Paraíba & 10 a 72,22 & Bovinos \\
2012 & Dalto et al. & Rio Grande do Sul & 20 & Bubalinos
\end{tabular}

tudados e utilizados como antígenos para aumentar a especificidade do teste ELISA, assim como para a elaboração de vacinas contra a paratuberculose, devido ao seu papel no processo patogênico (Stevenson \& Sharp 1997, Jolly et al. 2011).

No intuito de avaliar a ocorrência de reações cruzadas, Gomes et al. (2002) compararam os resultados do ELISA com e sem a etapa de pré-adsorção de anticorpos séricos inespecíficos, com a micobactéria ambiental M. phlei e, constataram que a não adsorção do soro, pode resultar em falso-positivo. Ainda, os autores relataram que os valores obtidos no estudo poderiam estar acima do "valor real", devido ao efeito aditivo da infecção pelo $M$. bovis e/ou $M$. avium, pois o tratamento das amostras com M. phlei poderia não eliminar os anticorpos dirigidos para esses agentes. Recentemente, Lilenbaum et al. (2009), através do teste ELISA, avaliaram a interferência da tuberculose bovina no diagnóstico sorológico da paratuberculose e relataram que a tuberculose pode prejudicar a especificidade dos testes diagnósticos para detecção da infecção pelo Map e comprometer a confiabilidade dos programas de controle no Brasil.

Apesar de o ELISA ser o teste mais utilizado para o monitoramento da infecção em nível de rebanho, Ferreira et al. (2002), Gomes et al. (2002) e Ristow et al. (2007) utilizaram o teste de AGID para estimar a prevalência da paratuberculose em rebanhos bovinos. Gomes et al. (2002) relataram que o teste apresentou boa sensibilidade e especificidade para confirmação da infecção em bovinos com sinais clínicos da enfermidade, no entanto, o teste apresenta menor sensibilidade em relação ao ELISA, inclusive em pequenos ruminantes (Gumber et al. 2006). Outros pesquisadores brasileiros (Ferreira et al. 2002, Ristow et al. 2007) relataram baixa sensibilidade do teste AGID para bovinos.

Os estudos sorológicos da paratuberculose realizados nos rebanhos nacionais demonstraram variação significativa dos resultados (Quadro 2), o que evidencia a necessidade de padronizações dos testes a fim de otimizar tanto a sensibilidade quanto a especificidade diagnóstica; desta forma, a confirmação do diagnóstico deve ser realizada em associação com outras técnicas laboratoriais (Berhs \& Collins 2010).

\section{Biologia molecular}

Os avanços da biologia molecular possibilitam a caracterização de cepas de Map e o desenvolvimento de pesquisas voltadas para a diferenciação entre as espécies de micobactérias potencialmente patogênicas. Várias técnicas moleculares tais como imunoeletroforese cruzada (CIE, "crossed immuno electro-phoresis") (Olsen et al. 2000), eletroforese em gel de sódio dodecyl sulfato-poliacrilamida (SDS-PAGE, "sodium dodecyl sulphate polyacrilamide gel electrophresis") (Gumber et al. 2007) e "western blotting" (Nikbakht-Brujeni \& Garibi 2012, Souza et al. 2012) têm sido eficiente na identificação de proteínas espécie específica. Atualmente, testes baseados na PCR ("polymerase chain reaction") e "real time" PCR têm sido ferramentas importantes na identificação de elementos genéticos, além de aumentar consideravelmente a sensibilidade dos testes para detecção de animais com a infecção subclínica (Castellanos et al. 2010, Timms et al. 2011, Logar et al. 2012).

Uma das principais diferenças entre Map e outras bactérias do complexo M. avium é a presença de 14 a 18 cópias do elemento de inserção IS900 no genoma do Map (Green et al. 1989); é o fragmento de DNA mais utilizado para detecção da micobactéria através da PCR (Vansnick et al. 2004, Imirzalioglu et al. 2011, Timms et al. 2011). As sequências de inserção são segmentos de DNA relativamente curtos capazes de se transpor, de se inserir de forma aleatória e ocupar múltiplos locais no genoma de procariotas, e causa frequentemente, mutação de inserção e rearranjos dos cromossomos (Motiwala et al. 2006). Em certos casos, os fragmentos específicos com localização definida no genoma, podem ser utilizados em estudos epidemiológicos como marcador para identificação de espécies ou diferenciação entre as cepas de microrganismos (Dombek et al. 2000). A presença de múltiplas cópias desta sequência no cromossomo do Map eleva a sensibilidade dos testes quando comparados com testes que utilizam como alvos os fragmentos genéticos únicos (Li et al. 2005, Sohal et al. 2009, Soumya et al. 2009, Imirzalioglu et al. 2011). Além do IS900, tem sido utilizado o IS1311 (Sohal et al. 2009, Timms et al. 2011), o F57, sequencia subspécie específica (Green et al. 1989, Poupart et al. 1993, Tsara \& Stephan 
2005, Kralik et al. 2011, Timms et al. 2011) , o alvo 251 (Rajeev et al. 2005), ISMAP02 (Paustian et al. 2004, Li et al. 2005, Stabel \& Bannantine 2005), ISMav2 (Strommenger et al. 2001, Schonenbrucher et al. 2008), o gene hspX (Schonenbrucher et al. 2008) e "open reading frames" (ORFs) MAP0865 e MAP2765c (Imirzalioglu et al. 2011), sequencias que podem ser considerados instrumentos valiosos para otimizar a especificidade de testes diagnósticos.

Outros marcadores genéticos como o LSPs ("large sequence polimorphims") e SSPs ("short sequence polimorphisms") foram utilizados para caracterização de Map em diferentes espécies de ruminantes, e também tem sido empregada em estudos epidemiológios (Amonsin et al. 2004, Ghadiali et al. 2004, Sohal et al. 2009). Semret et al. (2006) demonstraram que o LSPs no Map cofidica genes importantes responsáveis por enzimas metabólicas, fatores de virulência e proteínas antigênicas. A utilização de endonucleases de restrição (RFLP, "restriction fragment length polymorphisms" e PFGE, "pulsed field gel eletroforesis") permitem a diferenciação entre as cepas de Map (Sevilla et al. 2007, Stevenson et al. 2009, Sohal et al. 2010), o que pode auxiliar na determinação das variações genéticas e seus respectivos graus de virulência e patogenicidade, assim como na compreensão de sua patogênese (Sohal et al. 2009). Esta técnica também pode ser utilizada na identificação de regiões únicas presentes no genoma, como no RFLP de IS6110 do M. tuberculosis (Kanduma et al. 2003) e IS1245 de M. avium (Dvorska et al. 2004). François et al. (1997), através desta técnica, observaram semelhança dos isolados de Map provenientes de bovinos com a doença de Johne e de pacientes com a doença de Crohn. Adicionalmente, alguns autores utilizaram genes do rRNA, 16S, 23S e 5S, para o estudo de Map (Ji et al. 1994, Zakham et al. 2012). Outros pesquisadores utilizaram o "multilocus enzyme electrophoresis" (MEE), cujo teste apresenta maior sensibilidade e rapidez em relação ao RFLP e PFGE, além de requerer menor quantidade de DNA para o teste (Lee et al. 1994).

No Brasil, a partir de 2005, iniciaram-se estudos moleculares com a utilização da PCR para detecção de alguns fragmentos genéticos de Map, o IS900, F57 e ISMav2 em bovinos (Rodrigues et al. 2005, Ristow et al. 2007, Carvalho 2008, Mota et al. 2010, Yamasaki et al. 2010) e em búfalos (Mota et al. 2010, Dalto et al. 2012). Até o momento, estudos com o uso da PCR têm sido realizados para a confirmação do diagnóstico, a partir da suspeita clínica e achados anatomo-histopatológicos. Carvalho et al. (2012) avaliaram a conservação genética do fragmento IS900 amplificado a partir de leite bovino "in natura" no estado de Minas Gerais, cujos produtos foram clonados, sequenciados e comparados com as informações disponíveis no GenBank. Os pesquisadores verificaram o número de mutações em cada haplotipo e constataram que a sequencia IS900 está conservada e pode ser uma ferramenta molecular confiável para estudos epidemiológicos. Neste contexto, a análise molecular de fragmentos do genoma poderia ser utilizada no diagnóstico complementar de pesquisas sobre a distribuição geográfica dos padrões moleculares de Map (Castellanos et al. 2009) detectados em diferentes espécies e regiões geográficas.

\section{CONSIDERAÇÕES FINAIS}

Em geral, os aspectos clínico-patológicos da paratuberculose em bovinos e búfalos no Brasil, são semelhantes e observa-se marcada diarreia, lesões macro e microscópicas em intestino e linfonodos mesentéricos de forma mais evidente quando comparados aos ovinos e caprinos. Mucosa intestinal com áreas de ulcerações multifocal e pigmentação marrom-amarelado foi observada apenas em ovinos.

Não há informações suficientes que forneçam a origem da infecção nas diferentes espécies de ruminantes; o estudo da diversidade genética entre as cepas de Map de várias regiões do país pode auxiliar em estudos epidemiológicos e esclarecer, inclusive, a possibilidade de transmissão interespecífica do patógeno e, desta forma, gerar dados importantes para o direcionamento de medidas profiláticas estratégicas. Os estudos moleculares do Map no Brasil, ainda são escassos e estão voltados, em sua maioria, para diagnóstico e confirmação da infecção. No entanto, a tecnologia molecular permite a identificação de diferentes cepas do agente que, em conjunto com as informações epidemiológicas e clínico-patológicos da doença de Johne já existentes em diversas espécies de ruminantes e regiões do país, possibilitariam o desenvolvimento de estudos focados na caracterização da patogenicidade e virulência do agente infeccioso.

A presença da paratuberculose em quase todo território nacional, salienta a necessidade de medidas sanitárias da enfermidade no país. 0 desenvolvimento de pesquisas com o intuito de construir bases para um programa sanitário adequado à situação epidemiológica da paratuberculose do país e a pesquisa continuada em universidades e centros de pesquisa no Brasil, podem gerar dados importantes que possibilitem estimar, com mais confiabilidade, os prejuízos econômicos e sociais causados pela presença e manutenção de rebanhos infectados com Map no país. A partir da obtenção de dados reais, tornam-se coerentes os investimentos voltados para a capacitação técnica do diagnóstico da paratuberculose, tanto em nível de campo quanto laboratorial.

\section{REFERÊNCIAS}

Acypreste C.S., Juliano R.S., Riveira F.E.B., Silva L.A.F., Fioravanti M.C.S. \& Dias-Filho F.C. 2005. Uso da técnica do ELISA indireto na detecção de anticorpos anti-Mycobacterium paratuberculosis em vacas em lactação. Ciênc. Anim. Bras. 6(1):55-59.

Aly S.S., Mangold B.L., Whitlock R.H., Sweeney R.W., Anderson R.J., Jiang J., Schukken Y.H., Hovingh E., Wolfgang D., VanKessel J.A., Karns J.S., Lombard J.E., Smith J.M. \& Gardner I.A. 2010. Correlation between Herrold egg yolk medium culture and real-time quantitative polymerase chain reaction results for Mycobacterium avium subspecies paratuberculosis in pooled fecal and environmental samples. J. Vet. Diagn. Invest. 22(5): 677-683.

Amonsin A., Li L.L., Zhang Q., Bannantine J.P., Motiwala A.S., Sreevatsan S. \& Kapur V. 2004. Multilocus short sequence repeat sequencing approach for differentiating among Mycobacterium avium subsp. paratuberculosis strains. J. Clin. Microbiol. 42:1694-1702.

Autschbach F., Eisold S., Hinz U., Zinser S., Linnebacher M., Giese T., Loffer T., Buchler M.W. \& Schmidt J. 2005. High prevalence of Mycobacterium avium subspecies paratuberculosis IS900 DNA in gut tissues from individuals with Crohn's disease. Gut 54:944-949.

Ayele W.Y., Svastova P., Roubal P., Bartos M. \& Pavlik I. 2005. Mycobacte- 
rium avium subspecies paratuberculosis cultured from locally and commercially pasteurized cow's milk in the Czech Republic. Appl. Environ. Microbiol. 71(3):1210-1214.

Bannantine J.P., Zhang Q., Li L.L. \& Kapur V. 2003. Genomic homogeneity between Mycobacterium avium subsp. avium and Mycobacterium avium subsp. paratuberculosis belies their divergent growth rates. BMC Microbiol. 3:10.

Bannantine J.P., Paustian M.L., Kapur V. \& Eda S. 2010 Proteome and antigens of Mycobacterium avium subsp. paratuberculosis. In: Berhs M.A. \& Collins D.M. (Eds), Paratuberculosis: Organism, disease, control. CAB International, Cambridge. 375p.

Barbosa J.D., Oliveira C.M.C., Silveira J.A.S., Albernaz T.T., Silva N.S., Reis A.S.B., Oliveira C.H.S. \& Yamasaki E.M. 2010. Paratuberculosis in water buffaloes (Buballus bubalis) in Maranhão State, Brazil. Anais XXVI World Buiatrics Congress. Santiago, Chile.

Begg D.J. \& Whittington R.J. 2008. Experimental animal infection models for Johne's disease, an infectious enteropathy caused by Mycobacterium avium subsp. paratuberculosis. Vet. J. 176:129-145.

Behr M.A. \& Collins D.M. 2010. Paratuberculosis: Organism, disease, control. CAB international, Cambridge. 375p.

Brees D.J., Reimer S.B., Cheville N.F., Florance A. \& Thoen C.O. 2000. Immunohistochemical detection of Mycobaterium paratuberculosis in formalin-fixed, paraffin-embedded bovine tissue sections. J. Vet. Diagnost. Invest. 12:60-63.

Buergelt C.D., Williams E., Monif G.R.G., Pinedo P. \& Decker J.H. 2006. Nested polymerase chain reaction in prenatal detection of Mycobacterium avium subspecies paratuberculosis (Map) in bovine allantoic fluid and fetuses. Int. J. Appl. Res. Vet. Med. 14:232-238.

Carvalho I.A. 2008. Isolamento e detecção molecular de Mycobacterium avium subsp. paratuberculosis (Map) em rebanhos bovinos leiteiros na região de Viçosa, MG. Dissertação de Mestrado em Medicina Veterinária, UFV, Viçosa.

Carvalho I.A., Silva V.O., Vidigal P.M.P., Silva-Junior A. \& Moreira M.A.S. 2012. Genetic evaluation of IS 900 partial sequence of Mycobacterium avium subsp. paratuberculosis Brazilian isolates from bovine milk. Trop. Anim. Health Prod. S11250-012-0117-1. (Online)

Castellanos E., Aranaz A., Juan L., Álvarez J., Rodríguez S., Romero B., Bezos J., Stevenson K., Mateos A. \& Domínguez. 2009. Single nucleotide polymorphisms in the IS900 sequence of Mycobacterium avium subsp. paratuberculosis are strain type specific. J. Clin. Microbiol. 47(7):22602264.

Castellanos E., Aranaz A. \& Buck J. 2010. Rapid identification and differentiation of Mycobacterium avium subspecies paratuberculosis types by use of real-time PCR and high-resolution melt analysis of the MAP1506 locus. J. Clin. Microbiol. 48(4):1474-1477.

Chiodini R.J., VanKruiningen H.J. \& Merkal R.S. 1984a. Ruminant paratuberculosis (Johne's disease): The current status and future prospects. Cornell Vet. 74:218-262.

Chiodini R.J., Van Kruiningen H.J., Thayer W.R., Merkal R.S. \& Coutu J.A. 1984b. Possible role of mycobacteria in inflamatory bowel disease. Digest. Dis. Sci. 29:1073-1079.

Clarke C.J. 1997. The pathology and patogenesis of paratuberculosis in ruminants and other species. J. Comp. Pathol. 116:217-261.

Clarke C.J. \& Little D. 1996. The pathology of ovine paratuberculosis: Gross and histological changes in the intestine and other tissues. J. Comp. Pathol. 114(4):419-437.

Clarke R.G., Griffin J.F.T. \& Mackintosh C.G. 2010. Johne's diasease caused by Mycobacterium avium subsp. paratuberculosis infection in red deer (Cervus elaphus): an histopathological grading system and comparison of paucibacillary and multibacillary disease. N. Z. Vet. J. 58(2):90-97.

Clarke R.G., Griffin J.F.T. \& Mackintosh C.G. 2011. Modification to histopathological lesion severity score in red deer (Cervus elaphus) affected by Johne's disease. N. Z. Vet. J. 59(5):261-262.

Collins M.T., Lisby G., Moser C., Chicks D., Christensen S., Reichelderfer M., Hoiby N., Harms B.A., Thomsen O., Skibsted U. \& Binder V. 2000. Results of multiple diagnostic tests for Mycobacterium avium subsp. paratuber- culosis in patients with inflammatory bowel disease and in controls. J. Clin. Microbiol. 38:4373-4381.

Collins D.M., Zoete M. \& Cavaignac S.M. 2002. Mycobacterium avium subsp. paratuebrculosis strains from cattle and sheep can be distinguished by a PCR test based on a novel DNA sequence difference. J. Clin. Microbiol. 40:4760-4762.

Collins M.T., Gardner I.A., Garry F.B., Roussel A.J. \& Wells S.J. 2006. Consensus recommendations on diagnostic testing for the detection of paratuberculosis in cattle in the United States. J. Am. Vet. Med. Assoc. 229: 1912-1919.

Corpa J.M., Garrido J., García Marín J.F. \& Pérez V. 2000. Classification of lesions observed in natural cases of paratuberculosis in goats. J. Comp. Pathol. 122:255-265.

Coussens P.M. 2004. Model for immune responses to Mycobacterium avium subspecies paratuberculosis in cattle. Infect. Immun. 72:3089-3096.

Coussens P.M., Lamont E.A., Kabara E. \& Sreevatsan S. 2010. Host pathogen interactions and intracellular survival of Mycobacterium avium subsp. paratuberculosis. In: Berhs M.A. \& Collins D.M. (Eds), Paratuberculosis: Organism, disease, control. CAB International, Cambridge. 375p.

Crohn B., Ginzburg L. \& Oppenheimer G. 1932. Regional ileitis, a pathological and clinical entity. J. Am. Med. Assoc. 99:1323-1329.

Cunha P.H.J., Martins A.F., Fioravanti M.C.S., Brito L.A.B., Araújo E.G., Silva L.A.F., Rabelo R.E. \& Jardim E.A.G.V. 2003. Avaliação microbiológica e anatomopatológica da paratuberculose bovina: relato de caso. Encontro Nacional de Patologia Veterinária, Botucatu, p.118.

Dabbs D.J. 2010. Diagnostic Immunohistochemistry: Theranostic and genomic applications. $3^{\text {rd }}$ ed. Saunders Elsevier, Philadelphia.

Dacorso-Filho P., Campos I.O.N., Faria J.F. \& Langenegger J. 1960. Doença de Johne (paratuberculose) em bovinos nacionais. Arqs Inst. Biol. Anim., Rio de J., 3:129-139.

Dalto A.C., Bandarra P.M., Pavarini S.P., Boabaid F.M., Bitencourt A.P.G., Gomes M.P., Chies J., Driemeier D. \& Cruz C.E.F. 2012. Clinical and pathological insights into Johne's disease in buffaloes. Trop. Anim. Health Prod. 44:1-5.

Delgado F., Etchechoury D., Gioffré A., Paolicchi F., Viera F.B., Mundo S. \& Romano M.I. 2009. Comparison between two in situ methods for Mycobacterium avium subsp. paratuberculosis detection in tissue samples from infected cattle. Vet. Microbiol. 134:383-387.

Dias L.D., Assis R.A., Dias G.C.D., Junior A.C.O., Carvalho A.V.A., Pinto F.F., Gonçalves L.A., Martins N.E., Parreiras P.M. \& Nascimento R.P. 2002. Isolamento do Mycobacterium paratuberculosis a partir de fezes de bovinos suspeitos de paratuberculose. Semana de Iniciação Científica da Universidade Federal de Minas Gerais, Anais eletrônicos, Belo Horizonte, MG. Disponível em <http://www.ufmg.br/prpq/xisic/sic2002/ resumos/1w2w44.html> Acesso em 13 mai. 2012.

Dib C.C., DelFava E., Baldassi L., Arcaro J.R.P., Pozzi C.R. \& Roxo E. 2008. Aplicação do teste de ELISA para pesquisa de anticorpo anti-M. paratuberculosis em um rebanho bovino leiteiro, do Estado de São Paulo, sob monitoramento sanitário. 35ำ Congresso Brasileiro de Medicina Veterinária. Gramado, RS. Disponível em <http://www.sovergs.com.br/conbravet2008/anais/cd/resumos/R0774-1.pdf> Acessado em 28 jun. 2012.

Dombek P.E., Johnson L.K., Zimmerley S.T. \& Sadowsky M.J. 2000. Use of repetitive DNA sequences and the PCR to differentiate Escherichia coli isolates from humans and animal sources. Appl. Environ. Microbiol. 66:2572-2577.

Douarre P.E., Cashman W., Buckley J., Coffey A. \& O'Mahony J.M. 2010. Isolation and detection of Mycobacterium avium subsp. paratuberculosis (MAP) from cattle in Ireland using both traditional culture and molecular based methods. Gut Pathol. 2:11-17.

Douarre P.E., Cashman W., Buckley J., Coffey A. \& O’Mahony J.M. 2012. High resolution melting PCR to differentiate Mycobacterium avium subsp. paratuberculosis "cattle type" and "sheep type". J. Microbiol. Methods 88:172-174.

Driemeier D., Cruz C.E.F., Gomes M.J.P., Corbellini L.G., Loretti A.P. \& Colodel E.M. 1999. Aspectos clínicos e patológicos da paratuberculose em bovinos no Rio Grande do Sul. Pesq. Vet. Bras. 19(3/4):109-115. 
Dupont O. 1915. Jornal do Commércio do Rio de Janeiro de 5.11.1915.

Dvorska L., Matlova L., Bartos M., Parmova I., Bartl J., Svastova P., Bull T.J. \& Pavlik I. 2004. Study of Mycobacterium avium complex strains isolated from cattle in the Czech Republic between 1996 and 2000. Vet. Microbiol. 99:239-250.

Ferreira R., Fonseca L.S. \& Lilenbaum W. 2001. Detecção de anticorpos contra Mycobacterium paratuberculosis em rebanhos bovinos do Estado do Rio de Janeiro, Brasil. Revta Bras. Med. Vet. 23(4):19-24.

Ferreira R., Fonseca L.S. \& Lilenbaum W. 2002. Agar gel immunodifusion test (AGID) evaluation for detection of bovine paratuberculosis in Rio de Janeiro, Brazil. Letters Appl. Microbiol. 25:173-175.

Ferreira R., Ristow P., Marassi C.D., Rocha F., Oelemann W.M.R., Rodrigues A.B.F., Santos A.S.O., Carvalho E.C.Q., Carvalho C.B., Fonseca L.S. \& Lilenbaum W. 2003. Paratuberculose bovina em fazenda de produção leiteira em Resende, Rio de Janeiro, Brasil. 22ํㅡㄹ Congresso Brasileiro de Microbiologia, Florianópolis, SC. (CD-Rom)

Fonseca L.F.L., Olival A.A., Pereira C.C., Heinemann M.B., Richtzenhain L.J. \& Santos M.V. 2000. Identificação de anticorpos anti-Mycobacterium paratuberculosis em rebanhos bovinos leiteiros do Estado de São Paulo. Arqs Faculd. Vet. UFRGS 28:51-56.

François B., Frishnamoorthy R. \& Elion J. 1997. Comparative study of Mycobacterium paratuberculosis strains isolated from Crohn's disease and Johne's disease using restriction fragment length polymorphism and arbitrarily primed polymerase chain reaction. Epidemiol. Infect. 118:227-233.

Fukuda S., Hase K. \& Ohno H. 2011. Application of a mouse ligated Peyer's patch intestinal loop assay to evaluate bacterial uptake by M cells. J. Vis. Exp. 58:e3225.

Gatfield J. \& Pieters J. 2003. Molecular mechanisms of host-pathogen interaction: Entry and survival of mycobacteria in macrophages. Adv. Immunol. 81:45-96.

Ghadiali A.H., Strother M., Naser S.A., Manning E.J.B. \& Sreevatsan S. 2004. Mycobacterium avium subsp. paratuberculosis strains isolated from Crohn's disease patients and animal species exhibit similar polymorphic locus patterns. J. Clin. Microbiol. 142:5345-5348.

Gilot P. \& Massone M. 1994. Mycobacterium paratuberculosis and Escherichia coli share common antigenic determinants. Vet. Microbiol. 39:353360.

Gomes M.J.P., Driemeier D., Ribeiro V.R., Wunder Jr. E.A., Asanome W., Lanzon L.F. \& Wald V.B. 2002. Doença de Johne: Isolamento do Mycobacterium avium subsp. paratuberculosis (Map) em um rebanho leiteiro infectado na região Sul do Brasil. Acta Scient. Vet. 30(2):113-118.

Grant I.R. 2005. Zoonotic potential of Mycobcterium avium ssp. paratuberculosis: The current position. J. Appl. Microbiol. 98:1282-1293.

Grant I.R., Ball H.J. \& Rowe M.T. 2002. Incidence of Mycobacterium paratuberculosis in bulk raw and commercial pasteurized cow's milk from approved dairy processing establishments in the United Kingdom. Appl. Environ. Microbiol. 68(5):2428-2435.

Green E.P., Tizard M.L.V., Moss M.T., Thompson J., Winterbourne D.J., McFadden J.J. \& Hermon-Taylor J. 1989. Sequence and characteristics or IS900, an insertion element identified in a human Crohn's disease isolated or Mycobacterium paratuberculosis. Nucl. Acids Res. 17(22):9063-9073.

Gumber S., Eamens G. \& Whittington R.J. 2006. Evaluation of a pourquier ELISA kit in relation to agar gel immunodiffusion (AGID) test for assessment of the humoral immune response in sheep and goats with and without Mycobacterium paratuberculosis infection. Vet. Microbiol. 115:91-101.

Gumber S., Taylor D.L. \& Whittington R.J. 2007. Protein extraction from Mycobacterium avium subsp. paratuberculosis: Comparison of methods for analysis by sodium sodecyl sulphate polyacrylamide gel electrophoresis, native PAGE and surface enhanced laser desorption/ionization time of flight mass spectrometry. J. Microbiol. Methods 68(1):115-127.

Hendrick S.H., Kelton D.F., Leslie K.E., Lissemore K.D., Archambault M. \& Duffield T.F. 2005. Effect of paratuberculosis on culling, milk production, and milk quality in dairy herds. J. Am. Vet. Med. Assoc. 227(8):13021308.
Hermon-Taylor J. 2001. Mycobacterium avium subsp. paratuberculosis is a cause of Crohn's disease. Gut 49:755-756.

Imirzalioglu C., Dahmen H., Hain T., Billion A., Kuenne C., Chakraborty T. \& Domann E. 2011. Highly specific and quick detection of Mycobacterium avium subsp. paratuberculosis in feces and gut tissue of cattle and humans by multiple real-time PCR assays. J. Clin. Microbiol. 49(5):1843-1852.

Jacintho A.P.P., Simplício K.M.M.G., Garrido E., Magalhães G. \& Vasconcelos R.0. 2009. Paratuberculose em caprino. Anais XIV Encontro Nacional de Patologia Veterinária, São Paulo, SP.

Ji Y., Colston M.J. \& Cox R.A. 1994. Nucleotide sequence and secondary structures of precursor 16S rRNA of slow-growing mycobacteria. Microbiol. 140:123-132.

Johne N. \& Frothingham I. 1895. Ein eigentümlieher Fall von Tuberculose beim Rind. Dtsch. Z. Tiermed. 21:438- 454.

Jolly A., Colavecchia S.B., Fernandez B., Fernandez E. \& Mundo S.L. 2011. Antibodies induced by lipoarabinomannan in bovines: characterization and effects on the interaction between Mycobacterium avium subsp. paratuberculosis and macrophages in vitro. Vet. Med. Intern. 258479. (Online)

Jubb K.V.F., Kennedy P.C. \& Palmer N.C. 2007. Pathology of Domestic Animals. Vol.2, 5a ed. Saunders Elsevier, Edinbourgh.

Jungersen G., Huda A., Hansen J.J. \& Lind P. 2002. Interpretation of gamma interferon test for diagnosis of subclinical paratuberculosis in cattle. Clin. Diagn. Lab. Immunol. 9:453-460.

Kalis C.H., Collins M.T., Hesselink J.W. \& Barkema H.W. 2003. Specificity of two tests for the early diagnosis of bovine paratuberculosis based on cell-mediated immunity: The Johnin skin test and the gamma interferon assay. Vet. Microbiol. 97:73-86.

Kanduma E., McHugh T.D. \& Gillespie S.H. 2003. Molecular methods for Mycobacterium tuberculosis strain typing: a users guide. J. Appl. Microbiol. 94:781-791.

Kaur P., Filia G., Singh S.V., Patil P.K., Ravi-Kumar G.V. \& Sandhu K.S. 2011. Molecular epidemiology of Mycobacterium avium subspecies paratuberculosis: IS900 PCR identification and IS1311 polymorphism analysis from ruminants in the Punjab region of India. Comp. Immunol. Microbiol. Infect. Dis. 34(2):163-169.

Kheirandish R., Khodakaram-Tafti A. \& Hosseini A. 2008. The comparative evaluation of immunohistochemical and acid fast staining with histopathological changes in naturally occurring paratuberculosis in sheep. Comp. Clin. Pathol. 17:111-116.

Khodakaram-Tafti A. \& Rashidi K. 2000. The pathology of goat paratuberculosis: Gross and histopathological lesions in the intestines and mesenteric lymph nodes. Zoonosis Public Health 47(7):487-495.

Klanikova B., Slana I., Roubal P., Pavlik I. \& Kralik P. 2012. Mycobacterium avium subsp. paratuberculosis survival during fermentation of soured milk products detected by culture and quantitative real time PCR methods. Int. J. Food Microbiol. 157(2):150-155.

Kobayashi K., Blaser M.J. \& Brown W.R. 1989. Immunohistochemical examination for mycobacteria in intestinal tissues from patients with Crohn's disease. Gastroenterology 96:1009-1015.

Kralik P., Slana I., Kralova A., Babak V., Whitlock R.H. \& Pavlik I. 2011. Development of a predictive model for detection of Mycobacterium avium subsp. paratuberculosis in faeces by quantitative realt time PCR. Vet. Microbiol. 149:133-138.

Kruze J., Salgado M., Paredes E., Mella A. \& Collins M.T. 2006. Goat paratuberculosis in Chile: first isolation and confirmation of Mycobacterium avium subspecie paratuberculosis infection in a dairy goat. J. Vet. Diagn. Invest. 18:476-479.

Kurade N.P., Tripathi B.N., Rajukumar K. \& Parihar N.S. 2004. Sequencial development of histologic lesions and their relationship with bacterial isolation, fecal shedding and immune responses during progressive stages of experimental infection of lambs with Mycobacterium avium subsp. paratuberculosis. Vet. Pathol. 41:378-387.

Lee T.Y., Lee T.J. \& Kim S.K. 1994. Differentiation of Mycobacterium tuberculosis strains by arbitrarily primed polymerase chain reaction-based DNA fingerprinting. Yonsei Med. J. 35(3):286-294.

Li L., Bannantine J.P., Zhang Q., Amonsin A., May B.J., Alt D., Banerji N., Kan- 
jilal S. \& Kapur V. 2005. The complete genome sequence of Mycobacterium avium subspecies paratuberculosis. Proc. Natl Acad. Sci. 102(35): 12344-12349.

Lilenbaum W., Marassi C.D. \& Oelemann W.M.R. 2007. Paratuberculosis: An update. Braz. J. Microbiol. 38:580-590.

Lilenbaum W., Marassi C.D., Varges R., Medeiros L., Oelemann W.M.R. \& Fonseca L.S. 2009. Occurence of false-positive results in three paratuberculosis EISAs performed in a tuberculous herd. Vet. Res. Commun. 33:693-699.

Logar K., Kopinc R., Bandelj P., Staric J., Lapanje A. \& Ocepek M. 2012. Evaluation of combined high-efficiency DNA extraction and real-time PCR for detection of Mycobacterium avium subsp. paratuberculosis in subclinically infected dairy cattle: comparison with faecal culture, milk real-time PCR and milk ELISA. BMC Vet. Res. 8:49.

Losinger W.C. 2005. Economic impact of reduced milk production associated with Johne's disease on dairy operations in the USA. J. Dairy Res. 72(4):425-432.

McGavin M.D. \& Zachary J.F. 2007. Pathologic bases of veterinary disease. $4^{\text {th }}$ ed. Mosby, Missouri. 1476p.

Medeiros M.A., Garino-Junior F., Almeida A.P., Lucena E.A. \& Riet-Correa F. 2012a. Paratuberculose em ovinos e caprinos no estado da Paraíba. Pesq. Vet. Bras. 32(2):111-115.

Medeiros J.M.A., Garino-Júnior F., Matos R.A.T., Costa V.M.M. \& Riet-Correa F. 2012b. Frequência de anticorpos para paratuberculose em bovinos no semiárido paraibano. Pesq. Vet. Bras. 32(8):697-700.

Momotani E., Whipple D.L., Thiermann A.B. \& Cheville N.F. 1988. Role of M-cells and macrophages in the entrance of Mycobacterium paratuberculosis into domes of ileal Peyer's patches of calves. Vet. Pathol. 25:131-137.

Momotani E., Romona N.M., Yoshihara K., Momotani Y., Hori M., Ozaki H., Eda S. \& Ikegami M. 2012. Molecular pathogenesis of bovine paratuberculosis and human inflamatory bowel diseases. Vet. Immunol. Immunopathol. (In publication)

Mota R.A., Pinheiro-Junior J.W., Gomes M.J.P., Peixoto R.M., Maia C.L., Brito M.F., Chies J.A.B., Snel G.G.M., Bercht S. \& Juffo G.D. 2007. Paratuberculose em um rebanho leiteiro no Estado de Pernambuco, PE. Arqs Inst. Biológico, São Paulo, 74(2):73-79.

Mota P.M.P.C., Pires P.S., Assis R.A., Salvarani F.M., Leite R.M.H., Dias L.D., Leite R.C., Lobato F.C.F., Guedes R.M.C \& Lage A.P. 2009. Paratuberculosis in a dairy Gyr herd in a state of Paraíba, Brazil. Pesq. Vet. Bras. 29(9):703-706.

Mota R.A., Peixoto P.V., Yamasaki E.M., Medeiros E.S., Costa M.M., Peixoto R.M. \& Brito M.F. 2010. Ocorrência de paratuberculose em búfalos ( $B u$ balus bubalis) em Pernambuco. Pesq. Vet. Bras. 30(3):237-242.

Motiwala A.S., Li L., Kapur V. \& Sreevatsan S. 2006. Current understand of genetic diversity of Mycobacterium avium subsp. paratuberculosis. Microb. Infect. 8:1406-1418.

Nakajima M., Maia F.C.L. \& Mota P.M.P.C. 1991. Diagnóstico da paratuberculose em Minas Gerais. Anais 4ํㅗ Simpósio Brasileiro em Micobactérias, Bauru, SP, Resumo 67.

Naser S.A., Ghobrial G., Romero C. \& Valentine J.F. 2004. Culture of Mycobcterium avium subsp. paratuberculosis from blood of the patient with Crohn's disease. Lancet Infect. Dis. 364:1039-1044.

Nielsen S.S. \& Toft N. 2008. Ante morten diagnosis of paratuberculosis: A review of accuracies of ELISA, interferon g assay ad fecal culture techniques. Vet. Microbiol. 129:217-235.

Nikbakht-Brujeni G. \& Gharibi D. 2012. Development of DNA-designed avian IgY antibodies for detection of Mycobacterium avium subsp. $p a-$ ratuberculosis heat shock protein 70 (Hsp70) and anti-Hsp70 antibodies in the serum of normal cattle. Appl. Biochem. Biotechnol. 167(1): 14-23.

OIE 2012. World Organization for Animal Health. Disponível em <http:// www.oie.int/fileadmin/Home/eng/Health_standards/tahm/2.01.11_ PARATB.pdf> Acessado em 16 fev. 2012.

Okura H., Toft N. \& Nielsen S.S. 2012. Occurrence of Mycobacterium avium subsp. paratuberculosis in milk at dairy cattle farms: A systematic review and meta-analysis. Vet. Microbiol. 157:253-263.
Oliveira D.M., Pimentel L.A., Rodrigues T.A., Dantas A.F.M., Miranda-Neto E.G., Simões S.V.D. \& Riet-Correa F. 2008. Paratuberculose em bovinos no Estado da Paraíba. Anais Encontro Nacional do Diagnóstico Veterinário, Mato Grosso do Sul. (CD-Rom)

Oliveira D.M., Riet-Correa F., Galiza G.J.N., Assis A.C.O., Dantas A.F.M., Bandarra P.M. \& Garino F. 2010. Paratuberculose em caprinos e ovinos no Brasil. Pesq. Vet. Bras. 30(1):67-72.

Olsen I., Reitan L.J., Holstad G. \& Wiker H.G. 2000. Alkyl hydroperoxidase reductases $\mathrm{C}$ and $\mathrm{D}$ are major antigens constitutively expressed by $\mathrm{Myco-}$ bacterium avium subsp. paratuberculosis. Infect. Immun. 68(2):801-808.

Paolicchi F.A., Vagnozzi A., Morsella C.G., Verna A.E., Massone A.R., Portiansky E.L. \& Gimeno E.J. 2001. Paratuberculosis in red deer (Cervus elaphus): An immunohistochemical study. J. Vet. Med. 48:313-320.

Paustian M.L., Amonsin A., Kapur V. \& Bannantine J.P. 2004. Characterization of novel coding sequences specific to Mycobacterium avium subsp. paratuberculosis: implications for diagnosis of Johne's disease. J. Clin. Microbiol. 42:2675-2681.

Pérez V., García-Marín J.F. \& Badiola J.J. 1996. Description and classification of different types of lesion associated with natural classification of different types of lesion associated with natural paratuberculosis infection in sheep. J. Comp. Pathol. 114:107-122.

Pierce E.S. 2009. Where are all the Mycobacterium avium subspecies paratuberculosis in patients with Crohn's disease? PLoS Pathog. 5:e1000234.

Pithua P., Godden S.M., Wells S.J. \& Stabel J.R. 2011. Evalution of the risk of paratuberculosis in adult cows fed Mycobacterium avium subsp. paratuberculosis DNA-positive or negative colostrums as calves. Am. J. Vet. Res. 72(11):1456-1464.

PNCEBT 2006. Manual Técnico. Programa Nacional de Controle e Erradicação da brucelose e da Tuberculose Animal, Brasília. 184p.

Poester F.P. \& Ramos E.T. 1994. Infecção experimental em caprinos com Mycobacterium paratuberculosis de origem bovina. Ciência Rural 24:333337.

Portugal M.A.S.C., Pimentel J.N., Saliba A.M., Baldassi L. \& Sandoval E.F.D. 1979. Ocorrência de paratuberculose no Estado de Santa Catarina. Biológico, São Paulo, 4:19-24.

Rajeev S., Zhang Y., Sreevatsan S., Motiwala A.S. \& Byrum B. 2005. Evaluation of multiple genomic targets for identification and confirmation of Mycobacterium avium subsp. paratuberculosis isolates using real-time PCR. Vet. Microbiol. 105(3/4):215-211.

Ramos E.T., Poester F.P., Correa B.L., Oliveira S.J., Rodrigues N.C. \& Canabarro C.E. 1986. Paratuberculose em bovinos no estado do Rio Grande do Sul. Hora Vet. 6(34):28-32.

Ristow P., Marassi C.D., Rodrigues A.B.F., Oelemann W.M., Rocha F., Santos A.S.O., Carvalho E.C.Q., Carvalho C.B., Ferreira R., Fonseca L.S. \& Lilenbaum W. 2007. Diagnosis of paratuberculosis in a dairy herd native to Brazil. Vet. J. 174(2):432-434.

Ristow P., Rodrigues A.B.F., Fonseca L.S., Oelemann W.M.R., Souza G.N., Marassi C.D., Carvalho E.C.Q. \& Lilenbaum W. 2008. Correlation between pathological findings and bacteriological culture on paratuberculous cattle. Ciênc. Anim. Bras. 9(3):700-704.

Riveira F.E.B. 1996. Levantamento sorológico utilizando-se a técnica ELISA em rebanhos apresentando problemas reprodutivos. I. Enterite paratuberculose. Anais Encontro de Laboratórios de Diagnóstico Veterinário do Cone Sul. Campo Grande, MS, p.20-22.

Robbe-Austerman S. 2011. Control of paratuberculosis in small ruminants. Vet. Clin. North Am., Food Anim. Pract. 27(3):609-620.

Rodrigues A.B.F. 2005. Paratuberculose em bovinos: análises anátomo-clínica, bacteriológica, imunohistoquímica e pela reação em cadeia da polimerase. Tese de Doutorado no Curso de Pós-Graduação em Ciência Animal, Universidade Estadual do Norte Fluminense, Campos dos Goytacazes, RJ. 93p.

Rohde K.H., Abramovitch R.B. \& Russell D.G. 2007. Mycobacterium tuberculosis invasion of macrophages: linking bacterial gene expression to environmental cues. Cell Host and Microbe 2:352-364.

Santos J.A. \& Silva N.I. 1956. Sobre a 1a observação de paratuberculose no Brasil. Bolm Soc. Bras. Med. Vet. 24:5-14. 
Schonenbrucher H., Abdurnawjood A., Failing K. \& Bulte M. 2008. New triplex real-time PCR assay for detection of Mycobacterium avium subsp. paratuberculosis in bovine feces. Appl. Environ. Microbiol. 74:2751-2758.

Scott M.C., Bannantine J.P., Kaneko Y., Branscum A.J., Whitlock R.H., Mori Y., Speer C.A. \& Eda S. 2010. Absorbed EVELISA: A diagnostic test with improved specificity for Johne's disease in cattle. Foodborn Pathog. Dis. 7(11):1291-1296.

Semret M., Alexander D.C., Turenne C.Y., DeHaas P., Overduin P., VanSoolingen D., Cousins D. \& Behr M.A. 2005. Genomic polymorphisms for Mycobacterium avium subsp. paratuberculosis diagnostics. J. Clin. Microbiol. 43:3704-3712.

Sevilla I., Garrido J.M., Geijo M. \& Juste R.A. 2007. Pulsed-field gel eletrophoresis profile homogeneity of Mycobacterium avium subsp. paratuberculosis isolates from cattle and heterogeneity of those from sheep and goats. BMC Microbiol. 7:18-32.

Silva N.M. 1961. Estudos sobre a paratuberculose. II. Isolamento da amostra de Mycobacterium paratubeculosis em meio de Hohn. Arqs Inst. Biol. Anim., Rio de J., 4:175-178.

Silva N.M. 1968. Estudos sobre a paratuberculose. IV. Infecção experimental de ovino com Mycobacterium paratubeculosis de origem bovina. Pesq. Agropec. Bras. 3:285-289.

Silva E.B. 2005. Diagnóstico de paratuberculose em bovinos de corte do estado do Pará-Brasil. Dissertação de Mestrado em Ciência Animal, Universidade Federal do Pará, Castanhal. 60p.

Silva N.M. \& Pizelli G.N. 1961. Estudos sobre a paratuberculose. I. Diagnóstico de um caso da doença. Arqs Inst. Biol. Anim., Rio de J., 4:169-173.

Singh S.V., Singh A.V., Singh P.K., Gupta V.K., Kumar S. \& Vohra J. 2007. Seroprevalence of paratuberculosis in young kids using 'Bison type' $\mathrm{Myco-}$ bacterium avium subsp. paratuberculosis antigen in plate ELISA. Small Rumin. Res. 70(2/3):89-92.

Singh A.V., Singh S.V., Sohal J.S. \& Singh P.K. 2010. Genotype profiles of Mycobacterium avium subspecies paratuberculosis recovered from suspected and Crohn's disease patients in India. J. Commun. Dis. 42(2):91-100.

Sivakumar P., Tripathi B.N., Singh N. \& Sharma A.K. 2006. Pathology of naturally occurrence paratuberculosis in water buffaloes (Bubalus bubalis). Vet. Pathol. 43(4):455-462.

Slana I., Liapi M., Moravkova M., Kralova A. \& Pavlik I. 2009. Mycobacterium avium subsp. paratuberculosis in cow bulk tank Milk in Cyprus detected by culture and quantitative IS900 and F57 real-time PCR. Prev. Vet.Med 89(3/4):223-226.

Sohal J.S., Sheoran N., Narayanasamy K., Brahmachari V., Brahmachari V., Singh S. \& Subodh S. 2009. Genomic analysis of local isolated of Mycobacterium avium subspecies paratuberculosis. Vet. Microbiol. 134:375382.

Sohal J.S., Singh S.V., Singh P.K. \& Singh A.V. 2010. On the evolution of "Indian Bison type" strains of Mycobacterium avium subspescies paratuberculosis. Microbiol. Res. 165:163-171.

Soumya M.P., Pillai R.M., Antony P.X., Mukhopadhyay H.K. \& Rao V.N. 2009. Comparison of faecal culture and IS900 PCR assay for the detection of Mycobacterium avium subsp. paratuberculosis in bovine faecal samples. Vet. Res. Commun. 33:781-791.

Souza G.S., Rodrigues A.B., Gioffré A., Romano M.I., Carvalho E.C., Ventura T.L. \& Lasunskaia E.B. 2011. Apa antigen of Mycobacterium avium subsp. paratuberculosis as a target for species-specific immunodetection of the bacteria in infected tissues of cattle with paratuberculosis. Vet. Immunol. Immunopathol. 143(1/2):75-82.

Stabel J.R. 1997. An improved method for cultivation of Mycobacterium paratuberculosis from bovine fecal samples and comparison to three other methods. J. Vet. Diagn. Invest. 9:375-380.

Stabel J.R. 2010. Immunolgy of Paratuberculosis. Infection and Disease. In: Berhs M.A. \& Collins D.M. (Eds), Paratuberculosis: Organism, disease, control. CABI.org, Cambridge. 375p.

Stabel J.R. \& Bannantine J.P. 2005. Development of a nested PCR method targeting a unique multicopy element, ISMap02, for detection of Мyсоbacterium avium subsp. paratuberculosis in fecal samples. J. Clin. Microbiol. 43(9):4744-4750.
Stevenson K. \& Sharp J.M. 1997. The contribution of molecular biology to Mycobacterium avium subspecies paratuberculosis research. Vet. J. 153(3):269-286.

Stevenson K., Alvarez J., Bakker D., Biet F., Juan L., Denham S., Dimareli Z., Dohmann K., Gerlach G.F., Heron I., Kopecna M., May L., Pavlik I., Sharp M., Thibault V.C., Willemsen P., Zadocks R.N. \& Greig A. 2009. Occurrence of Mycobacterium avium subspecies paratuberculosis across host species and European countries with evidence for transmission between wildlife and domestic ruminants. BMC Microbiol. 9:212-224.

Strommenger B., Stevenson K. \& Gerlach G.F. 2001. Isolation and diagnostic potencial of ISMav2, a novel insertion sequence-like element from Mycobacterium avium subspecies paratuberculosis. FEMS Microbiol. Lett. 196(1):31-37.

Thorel M.F., Krichevsky M. \& Levy-Frebault V.V. 1990. Numerical taxonomy of mycobactin dependent mycobacteria, emended description of Mycobacterium avium and description of Mycobacterium avium subsp. avium subsp. nov., Mycobacterium avium subsp. paratuberculosis subsp. nov., and Mycobacterium avium subsp. silvaticum subsp. nov. Intern. J. Syst. Bacteriol. 40(3):254-260.

Timms V.J., Gehringer M.M., Mitchell H.M., Daskalopoulos G. \& Neilan B.A. 2011.Review. How accurately can we detect Mycobacterium avium subsp. paratuberculosis infection? J. Microbiol. Methods 85:1-8.

Tiwari A., Vanleeuwen J.A., McKenna S.L., Keefe G.P. \& Barkema H.W. 2006. Johne's disease in Canada. Part I. Clinical symptoms, pathophysiology, diagnosis, and prevalence in dairy herds. Can. Vet. J. 47:874-882.

Tripathi B.N., Sonawane G.G., Munjal S.K., Bind R.B., Gradinaru D., Dubey S.C., Mondal D., Paliwal O.P. \& Singh N. 2007. Seroprevalence of paratuberculosis in selected population of ruminants in India. Proc. $9^{\text {th }}$ International Colloquium on Paratuberculosis, Tsukuba, Japan, p.246-249.

Twort F.W. \& Ingram G.L. 1912. A method for isolating and cultivating the Mycobacterium enteritidis chronicae pseudotuberculosae bovis johne and some experiments on the preparation of a diagnostic vaccine for pseudo-tuberculous enteritis of bovines. Proc. Royal Society London 84:517-543.

USDA 2005. Animal and Plant Health Inspection Sheet: Highlights of NAHMS Johne's Disease on U.S. Dairy Operations, 2002, Washington, DC.

Vansnick E., Rijk P., Vercammen F., Geysen D., Rigouts L. \& Portaels F. 2004. Newly developed primers for the detection of Mycobacterium avium subspecies paratuberculosis. Vet. Microbiol. 100(3/4):197-204.

Webster J.D., Miller M.A., Dusold D. \& Ramos-Vara J. 2010. Effects of prolonged formalin fixation on the immunohistochemical detection of infectious agents in formalin-fixed, paraffin-embedded tissues. Vet. Pathol. 47(3):529-535.

Whittington R.J. \& Windsor P.A. 2009. In utero infection of cattle with Mycobacterium avium subsp. paratuberculosis: A critical review and meta-analysis. Vet. J. 179(1):60-69.

Whittington R.J., Taragel C.A., Ottaway S., Marsh I., Seaman J. \& Fridriksdottir V. 2001. Molecular epidemiological confirmation and circumstances of occurrence of sheep (S) strains of Mycobacterium avium subsp. paratuberculosis in cases of paratuberculosis in cattle in Australia and sheep and cattle in Iceland. Vet. Microbiol. 79:311-322.

Wynne J.W., Shiell B.J., Colgrave M.L., Vaughan J.A., Beddome G. \& Michalski W.P. 2012. Production and proteomic characterization of purified protein derivative from Mycobacterium avium subsp. paratuberculosis. Proteome Sci. 10:22.

Yakes B.J., Lipert R.J., Bannantine J.P. \& Porter M.D. 2008. Detection of Mycobacterium avium subsp paratuberculosis by a sonicate immunoassay based on surface-enhanced Raman scattering. Clin. Vaccine Immunol. 15:227-234.

Yamasaki E.M., Tokarnia C.H., Galvão A., Gomes M.J.P., Chies J.A.B., Veit T.D., Aragão A.P. \& Brito M.F. 2010. Aspectos clínicos patológicos e controle da paratuberculose em rebanho bovino leiteiro. Pesq. Vet. Bras. 30(11):921-932.

Zakham F., Belayachi L., Ussery D., Akrim M., Benjouad A., El-Aouad R. \& Ennaji M.M. 2012. Mycobacterial species as case-study of comparative genome analysis. Cell Mol. Biol. Suppl. 57. 